\title{
Complement-Derived Leukotactic Factors in
}

\section{Inflammatory Synovial Fluids of Humans}

\author{
Peter A. Ward and Nathan J. Zvatfler \\ From the Immunobiology Branch, Armed Forces Institute of Pathology, \\ Washington, D. C. 20305, and the Department of Medicine, Georgetown \\ University, School of Medicine, Washington, D. C. 20007
}

\begin{abstract}
A в S T R A C T A large per cent of rheumatoid synovial fluids contain chemotactic activity for rabbit granulocytes (neutrophilic). The chemotactic activity is, in large part, related to the fifth (C5) and sixth (C6) components of human complement; a combination of physical-chemical techniques indicates the activity to be attributable to $\overline{C 567}$ and $C 5 \mathrm{a}$, a cleavage product of C5. Many rheumatoid synovial fluids contain a C5-cleaving enzyme which, on the basis of substrate specificity and susceptibility to inhibitors, is very similar to an enzyme extractable from lysosomal granules of human and rabbit granulocytes. Inflammatory nonrheumatoid synovial fluids contain chemotactic activity that is related to cleavage products $(\mathrm{C} 3 \mathrm{a})$ of the third component of human complement (C3). Also found in these fluids is a C3-cleaving enzyme capable of producing C3a. Of the other synovial fluids examined, lupus fluids were remarkable by their total lack of chemotactic activity. These findings record for the first time the presence of complement-derived chemotactic factors in pathological human fluids.
\end{abstract}

\section{INTRODUCTION}

Inflamed joints, being almost invariably associated with synovial fluids rich in proteins as well as leukocytes, seem ideally suited to studies of mediators of the inflam-

The opinions or assertions contained herein are the private views of the authors and are not to be construed as official or as reflecting the views of the Department of the Army or the Department of Defense.

In conducting the research described in this report, the Investigators adhered to the "Guide for Laboratory Animal Facilities and Care," as promulgated by the Committee on the Guide for Laboratory Animal Facilities and Care of the Institute of Laboratory Animal Resources, National Academy of Sciences-National Research Council.

Dr. Zvaifler's present address is Department of Medicine, University Hospital, University of California at San Diego, San Diego, Calif. 92103.

Received for publication 25 June 1970 and in revised form 22 October 1970. matory response. In particular, rheumatoid synovial fluids are of special interest for two reasons. The content of neutrophilic leukocytes in these fluids is exceptionally high. In addition, the complement system in these fluids has undergone several alterations, which simulate those produced experimentally by sequential triggering of the complement system by an immune complex. Since activation of the complement sequence is known to result in the production of phlogistic factors, in particular chemotactic factors for leukocytes and vascular permeability-inducing factors (the anaphylatoxins), rheumatoid synovial fluids have been examined for the presence of chemotactic activity. In this report we describe our studies of synovial fluids from a variety of inflammatory joint diseases and demonstrate the presence of preformed chemotactic (leukotactic) factors as well as substances capable of generating chemotactic activity from the third (C3) or the fifth (C5) components of human complement. An understanding of these mediators may, at least in part, provide an explanation for the presence of leukocytes in synovial exudates of human diseases.

\section{METHODS}

Chemotactic assays. The micropore filter method has been used in chambers which have been previously described in detail $(1,2)$. Filters of the pore size $0.65 \mu$ (Millipore Corporation, Bedford, Mass.) were employed, chemotactic activity being expressed as the number of leukocytes that have responded to a chemotactic stimulus, as determined by counting cells that have migrated through five microscopic fields under high power. The indicator cell was the rabbit neutrophil obtained from a peritoneal exudate induced by the injection of $0.1 \%$ glycogen in saline (1). Fluids to be tested for chemotactic activity were diluted in tissue culture medium 199 (Microbiological Associates, Inc., Bethesda, Md.).

Antibody preparations to complement components. Antibody specific to human C3 or C5 was obtained by immunization of rabbits with purified human C3 or C5. As indicated below, $\mathrm{C} 3$ and $\mathrm{C} 5$ were purified by a combination of techniques including isoelectric precipitation, ion-exchange 
chromatography, hydroxyl apatite chromatography, and preparative electrophoresis. The resulting serum antibody preparations of anti-C3 or anti-C5 gave a single band after double diffusion in gel when tested against whole human serum or a euglobulin preparation of serum. The anti-C3 preparation did not react with purified human C5. However, because the anti-C5 preparation gave a very weak band when tested against purified human C3 $(3 \mathrm{mg} / \mathrm{ml})$, purified C3 was added in amounts of $100 \mu \mathrm{g} / \mathrm{ml}$ of antibody, which resulted in removal of the second band associated with antiC3 activity. The anti-C6 preparation was a gift from Dr. Peter J. Lachmann (University of Cambridge). This material consisted of rabbit IgG rich in antibody activity to rabbit $\mathrm{C} 6$, prepared by immunizing genetically C6-deficient rabbits with partly purified rabbit $\mathrm{C} 6$. This antiserum reacts well with human $\mathrm{C} 6$ to give a single preception band with whole serum and is entirely monospecific (3). In experiments where the suppressive effect of antibody on preformed chemotactic activity in synovial fluids was tested, $20 \mu 1$ of antibody was incubated with $50 \mu$ l of synovial fluid for $30 \mathrm{~min}$ at $37^{\circ}$ before chemotactic testing.

Inhibitors. $\xi$-Aminocaproic acid (EACA), tosyl arginine methyl ester (TAMe), benzoyl arginine methyl ester (BAMe), acetyl tyrosine ethyl ester (ATEe), and soybean trypsin inhibitor were employed as previously described (4). In order to determine the extent to which a given compound could interfere with generation of chemotactic activity from $\mathrm{C} 5$ by the C5-cleaving enzyme (4), each inhibitor was added before or after the $30 \mathrm{~min}$ period of incubation of synovial fluid with C5. Determining the per cent inhibition of chemotactic factor generating activity was possible by subtracting the chemotactic value of the mixture containing inhibitor added at the start of the period of incubation from the chemotactic value (control value) of the mixture to which inhibitor was added at the end of the period $(30 \mathrm{~min})$ of incubation at $37^{\circ} \mathrm{C}$. The ratio of this difference and the control value, times 100 , equals the per cent inhibition (4).

Ultracentrifugation and gel filtration. Using a sucrose density gradient from 5 to $35 \%$ in phosphate buffer $(\mathrm{pH}$ 7.3, ionic strength 0.05 ) samples were ultracentrifuged at $55,000 \mathrm{rpm}$ for $15 \mathrm{hr}$ at $4^{\circ} \mathrm{C}$, as described in detail elsewhere (2). Gel filtration was undertaken with Sephadex G-75 (Pharmacia Fine Chemicals Inc., Piscataway, N. J.) which had been equilibrated in and eluted with the same phosphate buffer (see above). Protein markers included bovine serum albumin (BSA), cytochrome c, and glucagon. These same protein markers have been used in previous experiments (4). The C6 assay was a hemolytic one, using C6-deficient rabbit serum as an indicator (1).

Electrophoresis. Preparative electrophoresis was carried out in Pevikon (5) using the neutral phosphate buffer described above.

Isolation of human C3 and C5. Human C3 and C5 were isolated by the procedures of Nilsson and Müller-Eberhard (6). Briefly, this consisted of isoelectric precipitation, ionexchange chromatography, and separation in hydroxyl apatite.

Human synovial fluids-patient material. Subjects with rheumatoid arthritis, inflammatory articular diseases other than rheumatoid arthritis, and traumatic and degenerative joint disease provided the synovial fluids used in this study. All rheumatoid patients met the American Rheumatism Association criteria for definite or classical rheumatoid arthritis. Their joint disease was of varying duration and severity, and all were receiving some medication including salicylates, corticosteroids, chloroquine, and gold salts. The group classified as inflammatory nonrheumatoid arthritis consisted of a variety of joint diseases characterized by synovitis with synovial fluid leukocyte counts greater than $2000 / \mathrm{mm}^{3}$. Included were six patients with Reiter's syndrome, five with ankylosing spondylitis, three with gouty arthritis, two with the arthritis of ulcerative colitis, single examples of chondrocalcinosis, rheumatic fever, and several different kinds of joint infections, and two subjects with undefined joint inflammation. The four patients with lupus erythematosus (LE) had mild synovitis, typical multisystem disease, and positive LE cell preparations. Patients with degenerative joint disease all had characteristic noninflammatory arthritis and typical radiologic and synovial fluid findings.

The methods employed for synovial fluid examination have been detailed elsewhere ( 7$)$. Fluid samples were obtained by aseptic aspiration of the suprapatellar pouch and immediately divided into aliquots for total and differential cell counts, mucin clot test, and microscopic examination for crystalline material. A portion was centrifuged in the cold, and the cell free supernatant was tested for total hemolytic complement activity.

\section{RESULTS}

Frequency of chemotactic activity in inflamed joint fluids. Synovial fluids from four general categories of inflammatory diseases of joints have been studied for preformed chemotactic activity (Table I). A relatively high incidence $(71 \%)$ of chemotactic activity has been found in rheumatoid synovial fluids, whereas half $(48 \%)$ of the fluids from patients with inflammatory nonrheumatoid arthritis contained preformed chemotactic activity. Two of three fluids from patients with gouty arthritis were chemotactically active, whereas none of

TABLE I

Chemotactic Activity in Human Synovial Fluids

\begin{tabular}{|c|c|c|}
\hline \multirow[b]{2}{*}{ Diagnosis } & \multicolumn{2}{|c|}{ Number positive* } \\
\hline & $\begin{array}{l}\text { Preformed } \\
\text { chemotactic } \\
\text { activity } \\
\text { (in } 100 \mu \mathrm{l} \text { ) }\end{array}$ & $\begin{array}{l}\text { C5-cleaving } \\
\text { activity }\end{array}$ \\
\hline Rheumatoid arthritis & $38 / 54(71 \%)$ & $7 / 3 \quad(54 \%)$ \\
\hline $\begin{array}{l}\text { Inflammatory, } \\
\text { nonrheumatoid } \\
\text { arthritis }\end{array}$ & $10 / 21(48 \%)$ & $4 / 13(31 \%)$ \\
\hline Gouty arthritis & $2 / 3 \quad(67 \%)$ & $1 / 3 \quad(33 \%)$ \\
\hline Lupus arthritis & $0 / 4 \quad(0)$ & $0 / 4 \quad(0)$ \\
\hline Osteoarthritis & $2 / 6 \quad(33 \%)$ & $0 / 2 \quad(0)$ \\
\hline
\end{tabular}

* Fluids contained chemotactic counts $>50$, with blank (negative) controls giving counts $<20$. In these assays positive controls consisting of highly active bacterial chemotactic factors from $E$. coli gave counts from 150 to 300 , depending on the experiment. The positive synovial fluids vary one from the other in degree of activity; no generalization can be made on degrees of activity in the various positive groups of fluids in Table I. 
TABLE II

Effect of Antibody to Complement on Chemotactic Activity in Rheumatoid Synovial Fluids

\begin{tabular}{cccc}
\hline & \multicolumn{3}{c}{$\begin{array}{c}\text { Reduction (per cent) in } \\
\text { chemotactic activity }\end{array}$} \\
\cline { 2 - 4 } $\begin{array}{c}\text { Antibody } \\
\text { added* }\end{array}$ & Fluid 1 & Fluid 2 & Fluid 3 \\
\hline None & 0 & 0 & 0 \\
Anti-C3 & 0 & 0 & 0 \\
Anti-C5 & 73 & 64 & 80 \\
Anti-C6 & 64 & 0 & 100 \\
\hline
\end{tabular}

* $50 \mu$ l antibody added to $100 \mu$ l synovial fluid. In this and in successive tables, positive fluids had counts of chemotactic activity from 125 to 320 in $100 \mu l$ synovial fluid.

the synovial fluids from four different patients with systemic lupus erythematosus were chemotactically active. To our surprise two of six fluids from osteoarthritis cases were chemotactically active. The incidence of C5-cleaving activity in the fluids will be discussed below.

Definition of chemotactic activity by use of antibodies to complement components. Three rheumatoid synovial fluids rich in chemotactic activity were analyzed antigenically for the possible relationship of the activity to complement components (Table II). Clearly evident is the fact that none of the rheumatoid fluids contained chemotactic activity suppressible with antibody to C3. On the other hand, each fluid contained activity, $64-80 \%$ of which could be suppressed with antibody to C5. In subsequent experiments at least 10 additional rheumatoid fluids have shown this pattern. Two of the three fluids also showed that the activity could be largely suppressed with antibody to C6. These data are in keeping with the concept that rheumatoid fluids possess chemotactic activity related to $\mathrm{C} 5$ and, in some cases, also to C6. Together with the ultracentrifugal data, to be presented below, the possibility exists that the activity is attributable to the macromolecular entity $\mathrm{C} \overline{567}$, whereas the cleavage product of $\mathrm{C} 5$ (see below), C5a, represents the slowly sedimenting chemotactic factor.

It should be pointed out that, whereas rheumatoid synovial fluids do not in general contain chemotactic activity related to $\mathrm{C} 3$, there are exceptions. In addition, it will be stressed in a later section that a whole class of nonrheumatoid synovial fluids contain C3-related chemotactic activity.

Ultracentrifugal behavior of chemotactic activity in synovial fluids. In order to define in physical-chemical terms the chemotactic activity in rheumatoid joint fluids, ultracentrifugal separation of these fluids was undertaken. Two general patterns in the localization of chemotactic activity were found. In the first, activity was macromolecular in behavior, appearing in the lower zones of the gradient, in the lower region of the profile for C6 (Fig. 1, fractions 2, 4, 6). A second pattern involving a multiphasic distribution of chemotactic activity was also found in joint fluids. In these cases, both a macromolecular factor (Fig. 2, fractions 4, 6) and a slowly sedimenting chemotactic factor (fraction 14,15) were seen.

Table III summarizes the data on a series of 18 rheumatoid synovial fluids subjected to chemotactic analysis

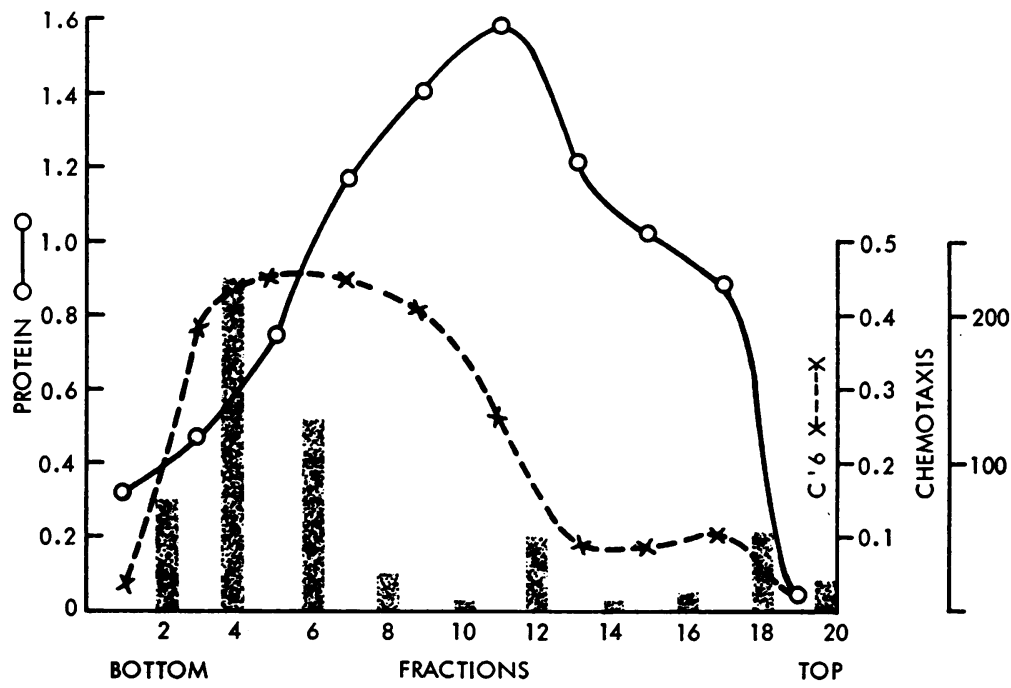

FIGURE 1 Density gradient analysis of joint fluid 7661. Ultracentrifugal analysis in a sucrose density gradient of chemotactic activity in a rheumatoid synovial fluid. Virtually all activity is in the lower regions of the gradient (fractions 2, 4, 6). See Fig. 2 for positions of reference proteins. Sedimentation is from right to left. 

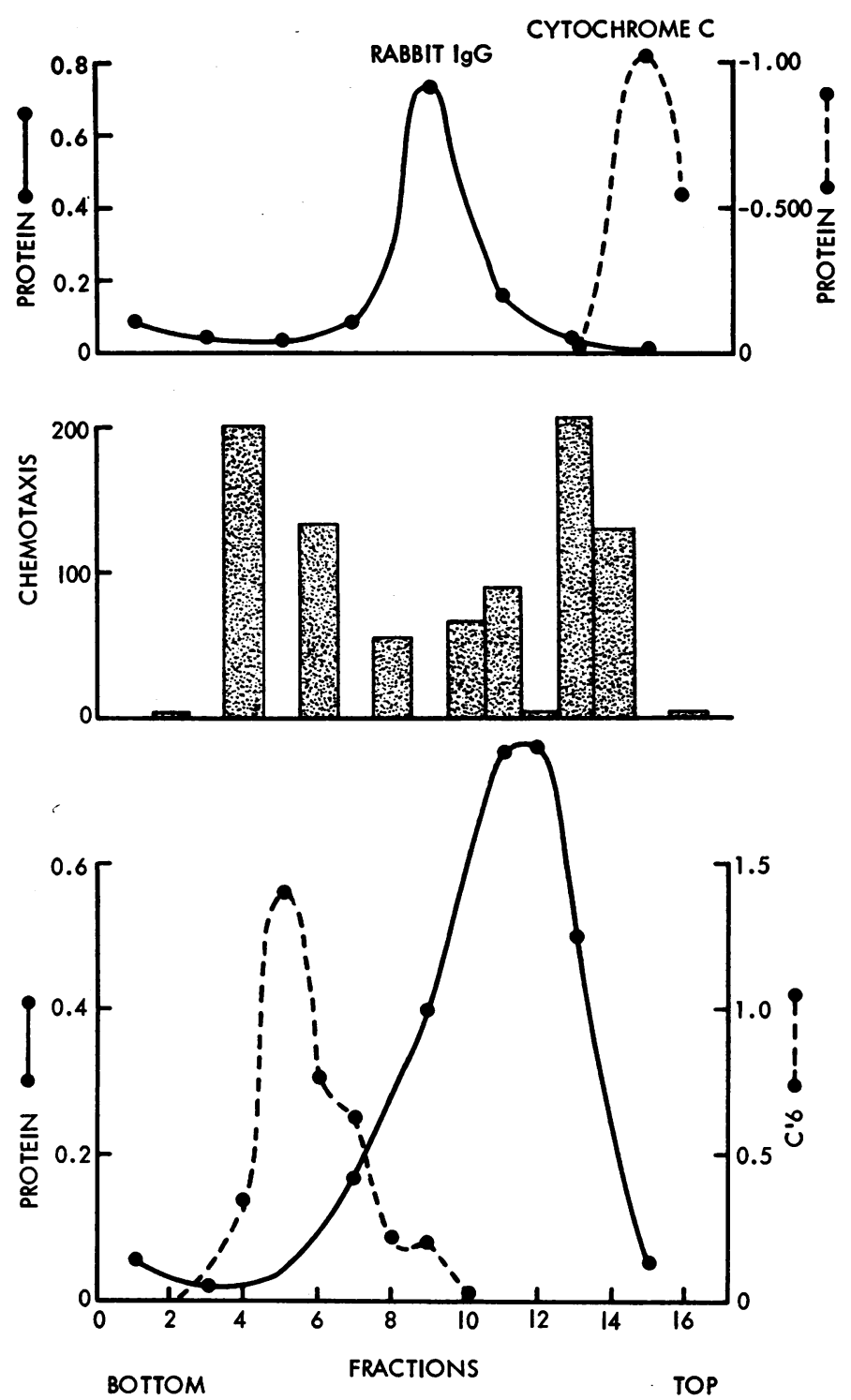

FIgURE 2 Analysis of rheumatoid arthritis synovial fluid in density sucrose gradient ultracentrifugation. Ultracentrifugal resolution of chemotactic activity in a rheumatoid synovial fluid into two zones of activity, in the upper and the lower regions of the gradient. Upper frame contains reference proteins.

after fractionation in sucrose density gradients. 12 of 18 fluids had zones of rapidly ("heavy") as well as slowly ("light") sedimenting chemotactic activity, whereas only 5 fluids showed activity limited to the rapidly sedimenting zone of the gradient. To date only one fluid has been found that contains activity totally ascribable to a slowly sedimenting chemotactic factor.

Of four inflammatory nonrheumatoid arthritis fluids so far examined by ultracentrifugation, none has had chemotactic activity of the rapidly sedimenting type, that is, appearing in a position below the IgG marker.
Analysis by molecular sieving of chemotactic activity in rheumatoid synovial fluids. A chemotactically active rheumatoid synovial fluid chromatographed on Sephadex G-75 at neutral $\mathrm{pH}$ revealed two major zones of chemotactic activity: one eluted just before the cytochrome c marker, and one coincident with the glucagon marker (Fig. 3). A fraction from each chemotactically active zone was tested for susceptibility to anti-C5, and in each sample the majority ( 55 and $89 \%$ ) of the chemotactic activity could be suppressed. These data indicate that the late eluting (and presumably lower molecular weight) 
TABLE III

Density Gradient Analysis of Chemotactic Activity in Rheumatoid Joint Fluids*

Total number of fluids tested 18

Number with "heavy" material only 5

Number with "heavy" and "light" material 12

Number with "light" material only

* "Heavy" refers to sedimentation velocity > IgG whereas "light" refers to sedimentation velocity < albumin.

chemotactic factors are, in large part, related antigenically to C5, which suggests that they are, in fact, cleavage products of $\mathrm{C} 5$.

C5 cleavage products and the C5-cleaving enzyme in rheumatoid synovial fluids. As Table I indicates, many of the synovial fluids were able to produce chemotactic activity upon the addition of purified human C5. In those experiments $20 \mu \mathrm{l}$ of synovial fluid (with $<50$ counts of chemotactic activity) was added to $50 \mu 1$ of purified C5 $[100 \mu \mathrm{g}]$ with $0.1 \mathrm{ml}$ of veronal buffer, $\mathrm{pH} \mathrm{7.4,} \mathrm{followed} \mathrm{by} \mathrm{incubation} \mathrm{for} 25 \mathrm{~min}$ at $37^{\circ} \mathrm{C}$. Fluids were then quickly chilled, diluted to $1.0 \mathrm{ml}$ with medium 199, and tested for chemotactic activity. Resulting chemotactic counts (usually $>200$ ) were corrected by subtraction of counts due to $\mathrm{C} 5$ alone and synovial fluids alone. The resulting corrected activity was usually still $>200$. With regard to the presence of an enzyme that interacts with $\mathrm{C} 5$ to produce chemotactic activity (it will be shown later that this involves cleavage of C5 with the liberation of active fragments), somewhat over half the rheumatoid fluids were found to contain this enzyme, whereas one-third of the inflammatory nonrheumatoid fluids contained a generator of chemotactic activity from C5 (Table I). Two of three fluids from patients with gouty arthritis were chemotactically positive; one of these two fluids generated activity from $\mathrm{C} 5$. None of the four cases of lupus arthritis was chemotactically positive nor did any generate chemotactic activity upon addition of C5. Of six cases of osteoarthritis two were chemotactically active, but neither generated chemotactic activity after addition of C5.

The nature of the activity generated with addition of C5 was studied by gel filtration (Fig. 4). Elution of a rheumatoid synovial fluid to which no $\mathrm{C} 5$ was added revealed three peaks of preformed chemotactic activity, one associated with the void volume (eluting before the BSA marker), and two peaks of activity eluting after the cytochrome marker (Fig. 4, lower frame). When the amount of synovial fluid was reduced from $200 \mu$ to 50 $\mu \mathrm{l}$ and incubated with $200 \mu \mathrm{g}$ of C5 (in a final volume of $300 \mu 1)$ for $30 \mathrm{~min}$ at $37^{\circ} \mathrm{C}$, the elution profile for chemotactic activity was somewhat altered (Fig. 4, upper frame). The early eluting chemotactic activity, presum-

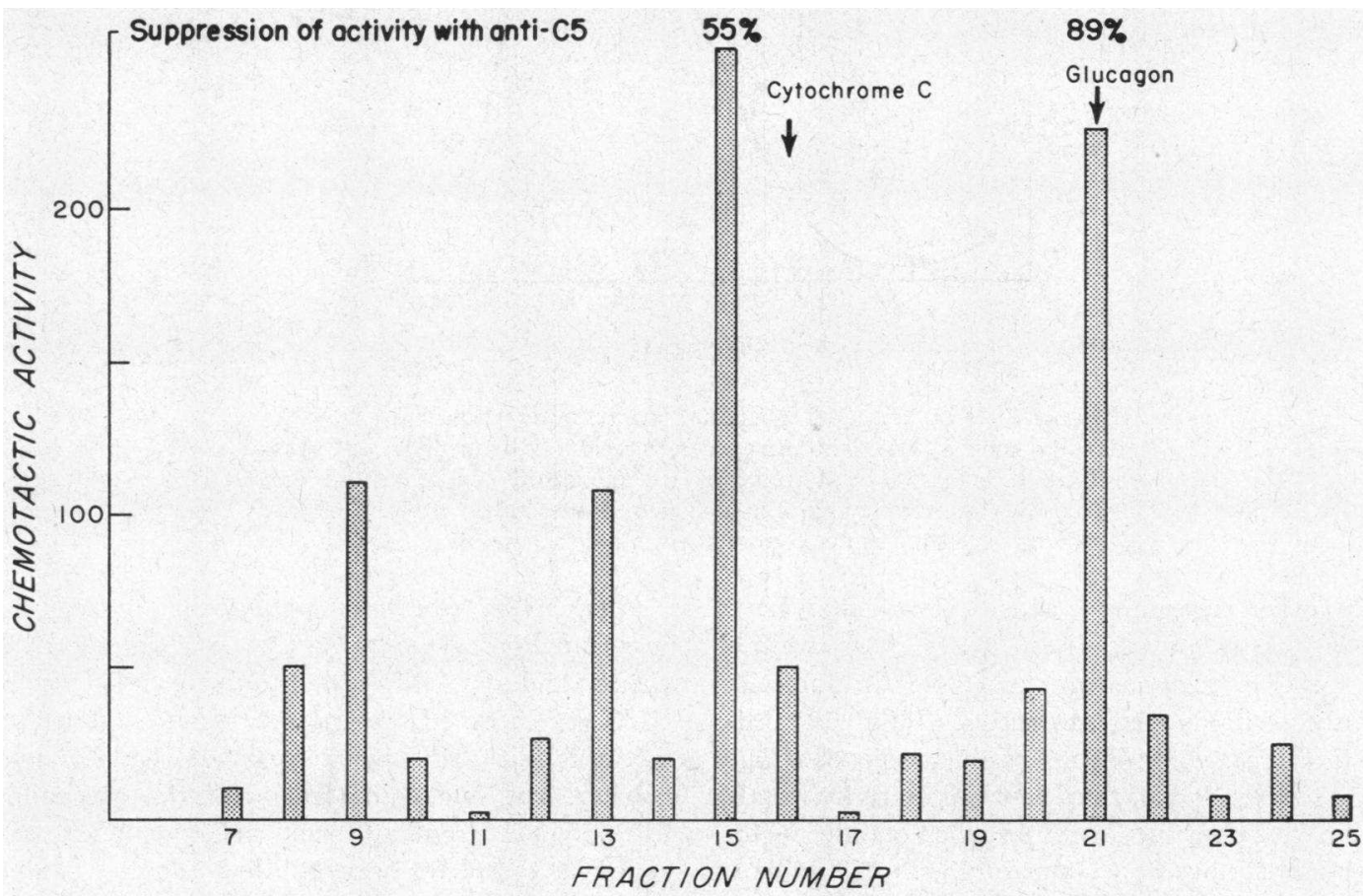

FIGURE 3 Separation of chemotactic activity in rheumatoid synovial fluid by elution from Sephadex G-75. Most of the activity elutes near the marker proteins, and most of the activity can be suppressed by anti-C5. 


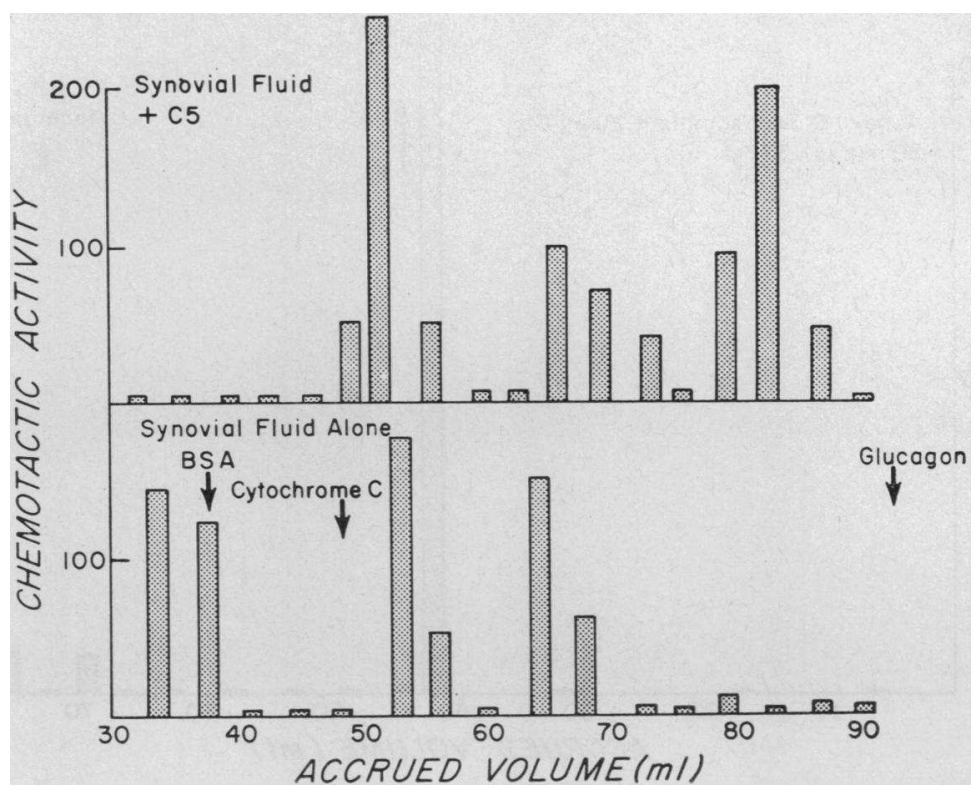

FIGURE 4 Sephadex G-50 fractionation of chemotactic activity in rheumatoid synovial fluid (lower frame) and localization of new activity generated by addition of $\mathrm{C5}$ to limiting amounts of the same synovial fluid (upper frame).

ably of relatively high molecular weight, was not found (due at least in part to limiting amounts of synovial fluid in this preparation), whereas two zones of chemotactic activity near to and retarded beyond the cytochrome marker were seen in positions similar to performed activity in the synovial fluid (Fig. 4, lower frame). In addition, a new, late eluting peak of activity appeared near the glucagon marker (Fig. 4, upper frame, $80-84 \mathrm{ml}$ ). The relatively large amount of chemotactic activity in the fractions of the upper frame compared with fractions of the lower frame suggests that most of the chemotactic activity in the mixture containing synovial fluid and added C5 (upper frame) was newly formed, being derived from interaction of the synovial fluid with $\mathrm{C}$. These results also suggest that rheumatoid synovial fluid interacts with $\mathrm{C} 5$ to produce chemotactic factors of relatively low molecular weight, and that some of these factors behave in gel filtration in a manner similar to those already present in the synovial fluid, whereas a third factor is dissimilar as judged by its very late position of elution from the gel.

A rheumatoid synovial fluid with ability to generate chemotactic activity from C5 was eluted from Sephadex G-75, and each fraction was then tested for its ability to generate chemotactic activity from $\mathrm{C} 5$. As indicated in Fig. 5, sharp localization of the C5-cleaving activity was found in the fraction (at $42 \mathrm{ml}$ ) eluting immediately before the position of the BSA marker. This suggests that the generator of C5-dependent chemotactic activity is a substance with a molecular weight of approximately 65,000 .

Addition of various inhibitors to a mixture of $\mathrm{C} 5$ and rheumatoid synovial fluid at the beginning of the $30 \mathrm{~min}$ period of incubation $\left(37^{\circ} \mathrm{C}\right)$ provided some definition of the C5-cleaving factor in the synovial fluid. EACA in a relatively high concentration $2 \times 10^{-8} \mathrm{moles} / \mathrm{liter}$ inhibited formation of $86 \%$ of the chemotactic activity when compared with the control specimen to which no inhibitor had been added. Soybean trypsin inhibitor in high quantity $(1.5 \mathrm{mg} / \mathrm{ml}$ of reaction inixture) led to $60 \%$ inhibition. The same agents, if withheld until the end of the incubation period, failed to interfere with generation of chemotactic activity from $\mathrm{C} 5$. That the chemotactic activity generated was C5-related and not due to generation of a factor from $\mathrm{C} 3$ or other substrates (preexisting in the synovial fluid) was shown by the use of specific antibody. Anti-C5 inhibited $72 \%$ of the newly formed chemotactic activity, whereas antiC3 was without effect on the activity.

A C5-cleaving enzyme in lysosomal granules of human leukocytes. Leukocytes, consisting predominantly of neutrophils $(90 \%)$, were obtained from a rheumatoid synovial fluid exudate. After isolation and disruption of lysosomal granules (4), the solubilized materials from these granules were shown to interact with $\mathrm{C} 5$ to produce chemotactic activity (Table IV). $20 \mu 1$, or the theoretical equivalent of lysosomal contents in $2.0 \times 10^{5}$ human neutrophils (assuming complete recovery), was added to $50 \mu \mathrm{l}$ of purified human C5 $(100 \mu \mathrm{g})$, under 


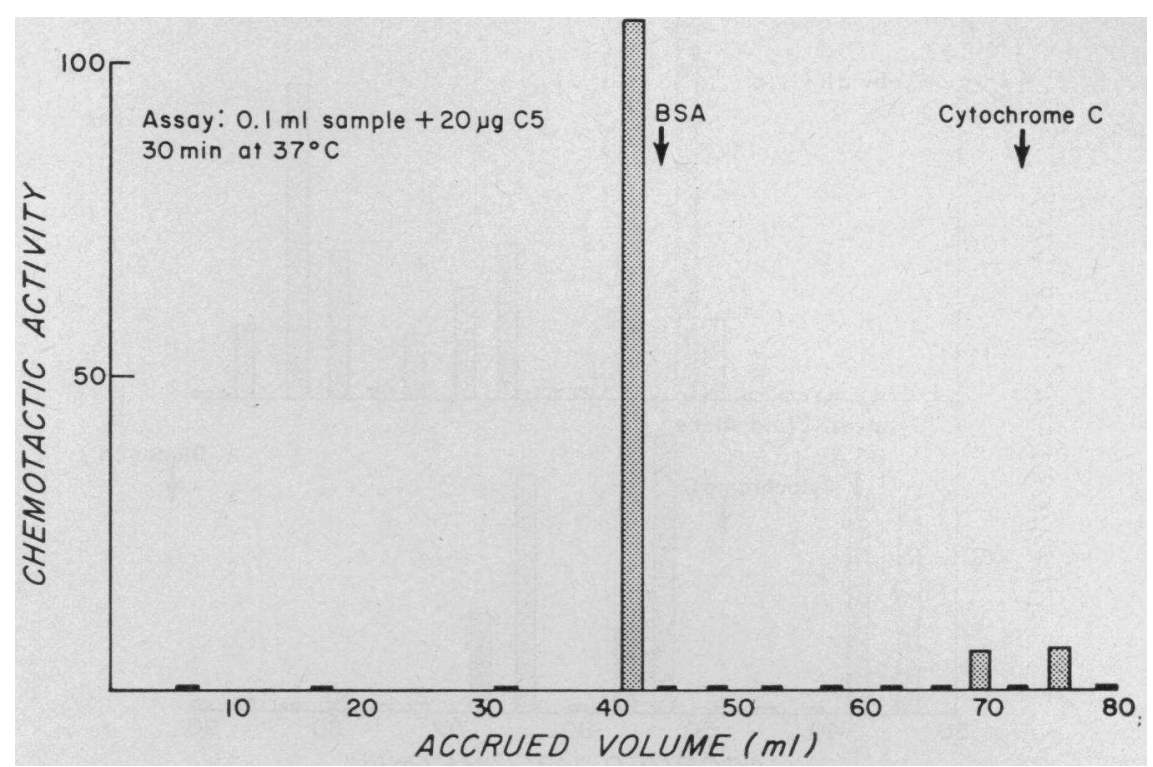

FIGURE 5 Elution from Sephadex G-75 of the C5-cleaving enzyme present in a rheumatoid synovial fluid. The enzyme elutes in a position close to the albumin marker.

conditions similar to those described above. Substantial chemotactic activity was generated with counts between 200 and 300 . This generator of chemotactic activity was susceptible to inhibition by EACA and soybean trypsin inhibitor as well as by TAMe and, to a lesser extent, by BAMe. ATEe had no effect. This susceptibility of the generator of C5-dependent chemotactic activity, as well as its lysosomal origin, are features very similar to the C5-cleaving enzyme derived from lysosomal granules of rabbit neutrophils (3).

The incidence of C3- and C5-related chemotactic activity in inflamed joint fluids. The data in Table V confirm the findings cited above where it was shown that a large per cent of rheumatoid synovial fluids con-

TABLE IV

Features of C5-Cleaving Activity in Lysosomal Granules of Human Leukocytes*

\begin{tabular}{lc}
\hline \multicolumn{1}{c}{ Inhibitor added $\ddagger$} & $\begin{array}{c}\text { Chemotactic activity } \\
\text { (\% reduction) }\end{array}$ \\
\hline None & 0 \\
EACA $\left(1.3 \times 10^{-2}\right.$ moles/liter $)$ & 83 \\
Trypsin inhibitor $(100 \mu \mathrm{g})$ & 83 \\
TAMe $\left(1.6 \times 10^{-2}\right.$ moles/liter $)$ & 49 \\
BAMe $\left(1.6 \times 10^{-2}\right.$ moles/liter $)$ & 25 \\
ATEe $\left(1.6 \times 10^{-2}\right.$ moles/liter $)$ & 0 \\
\hline
\end{tabular}

* Leukocytes from exudate of synovial fluid.

‡ Conditions as described in text. Reactive volume was $0.3 \mathrm{ml}$ with incubation at $37^{\circ} \mathrm{C}$ for $30 \mathrm{~min}$. tain C5-related chemotactic activity. Only 1 of 15 chemotactically active rheumatoid synovial fluids had activity that was completely suppressed by antibody to C3, whereas $53 \%$ of the fluids had activity completely suppressible with antibody to C5. On the basis of effects of anti-C3 and anti-C5, six fluids had both C3- and C5-related chemotactic activity. ${ }^{1}$ Quite in contrast, fluids from inflammatory nonrheumatoid joints showed a different pattern. The 9 cases are from the group of 21 cases listed in Table I but studied in greater detail. $56 \%$ of the nine fluids had activity totally suppressible by antibody to $\mathrm{C} 3$, a third had only C5-related activity, and $11 \%$ had both C3- and C5-related activity. These data suggest that a given fluid containing only C3related chemotactic activity is not likely to be from a patient with rheumatoid arthritis.

Comparison by ultracentrifugal characteristics of chemotactic activity in rheumatoid and nonrheumatoid synovial fluids. Two inflammatory joint fluids, one of

${ }^{1}$ In these experiments equal volumes $(100 \mu \mathrm{l})$ of antibody and synovial fluids were used. The mixtures were then incubated for $20 \mathrm{~min}$ at $37^{\circ} \mathrm{C}$, chilled to $0^{\circ} \mathrm{C}$, and diluted to $1.0 \mathrm{ml}$ in medium 199 for chemotactic testing. That some rheumatoid fluids $(40 \%)$ show suppression of chemotactic activity by antibody to $\mathrm{C} 3$ is not necessarily in conflict with the data in Table II, since in that experiment only half the amount of antibody was used. In the present experiments antibody to C3 rarely led to greater than $40 \%$ inhibition of chemotactic activity in the rheumatoid synovial fluids, whereas antibody to C5 usually inhibited as much as $80-90 \%$ of the total chemotactic activity. 
which was a rheumatoid fluid, were fractionated by ultracentrifugation and analyzed for chemotactic activity (Fig. 6). The rheumatoid fluid had the characteristic biphasic distribution (Fig. 6, lower frame) of activity which has been related to $\mathrm{C} \overline{567}$ and $\mathrm{C} 5 \mathrm{a}$ (see previous section). The inflammatory nonrheumatoid fluid (15138) also had a biphasic peak of chemotactic activity, but all activity was in the upper portion of the gradient, sedimenting more slowly than (that is, above) the albumin (BSA) marker. Antibody to C3 totally suppressed the activity in unfractionated fluid 15138, which suggests that the chemotactic activity was entirely related to C3 fragments.

Addition of $\mathrm{C} 3(200 \mu \mathrm{g})$ to $50 \mu \mathrm{l}$ of fluid 15138 resulted in the appearance of substantial chemotactic activity after incubation at $37^{\circ} \mathrm{C}$ for $\frac{1}{2} \mathrm{hr}$ at $\mathrm{pH} 7.3$. By density gradient ultracentrifugation, the fluid was fractionated in a sucrose gradient, and the fractions were analyzed for chemotactic activity. A nearly perfect duplicate of the pattern present in the upper portion of Fig. 6 was seen,
TABLE V

C3- and C5-Related Chemotactic Activity in Synovial Fluids as Determined by Use of Specific Antibody

\begin{tabular}{llll}
\hline & \multicolumn{3}{c}{ Number positive } \\
\cline { 2 - 4 } & $\begin{array}{c}\text { C3 activity } \\
\text { solely }\end{array}$ & $\begin{array}{c}\text { C5 activity } \\
\text { solely }\end{array}$ & Both \\
\hline Fluid tested (diagnosis) & $1 / 15(7 \%)$ & $8 / 15(53 \%)$ & $6 / 15(40 \%)$ \\
$\begin{array}{l}\text { Rheumatoid arthritis } \\
\begin{array}{l}\text { Inflammatory, } \\
\text { nonrheumatoid } \\
\text { arthritis }\end{array}\end{array}$ & $5 / 9(56 \%)$ & $3 / 9(33 \%)$ & $1 / 9(11 \%)$ \\
\end{tabular}

which indicates that the newly appearing chemotactic activity generated by addition of C3 was not different from that preformed chemotactic activity present in the original untreated synovial fluid.

Direct proof of C3-cleaving factor in fuid 15138. The above data strongly suggested that preexisting chemotactic activity in fluid 15138 was associated with C3-cleavage products and that a factor capable of gen-

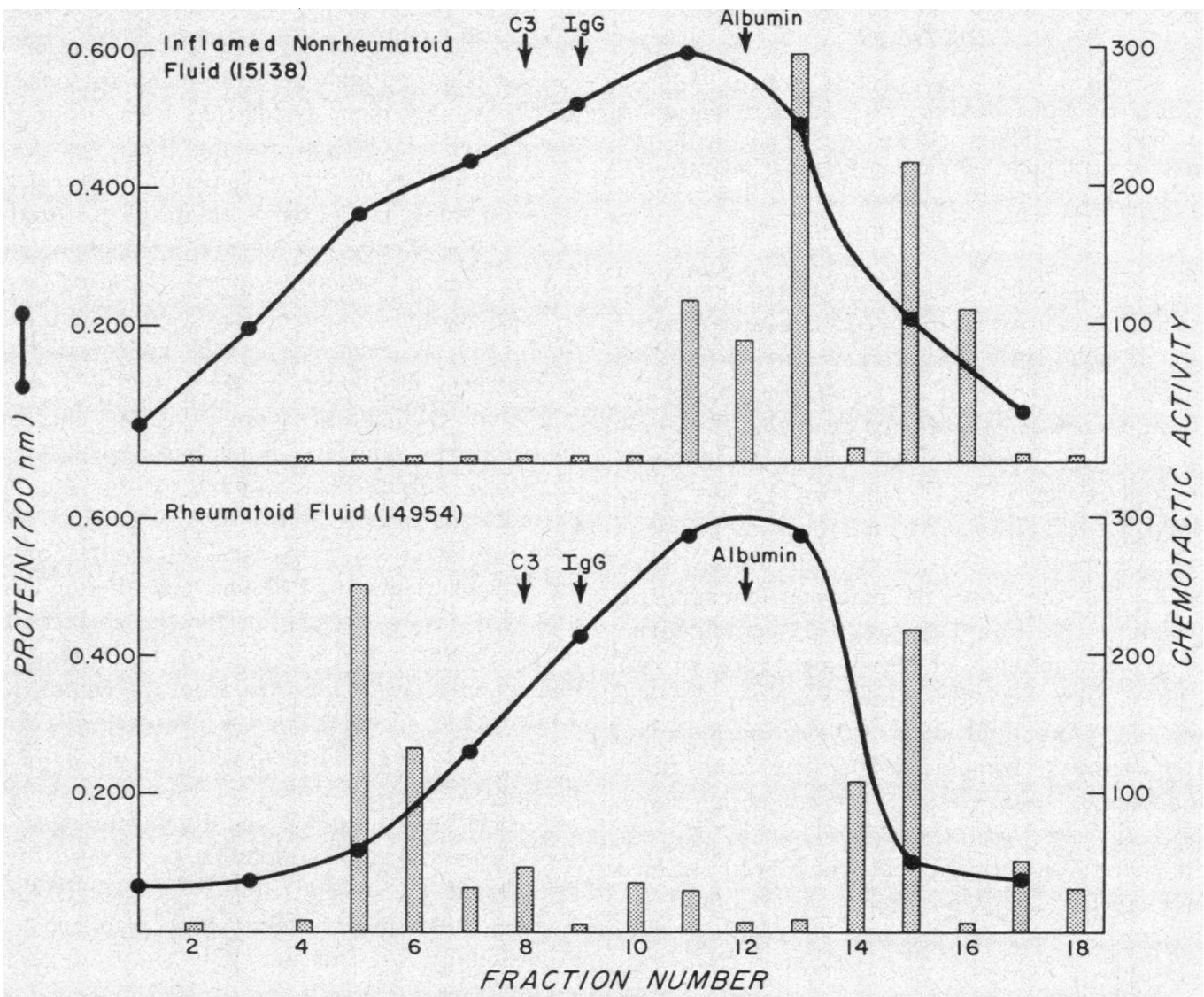

FIGURE 6 Density gradient analysis of chemotactic activity. Ultracentrifugal separation of a rheumatoid synovial fluid (lower frame) and a nonrheumatoid inflammatory synovial fluid (upper frame). The former fluid contains a "heavy" and a "light" zone of activity, whereas the latter fluid contains only a biphasic zone of "light" activity. 


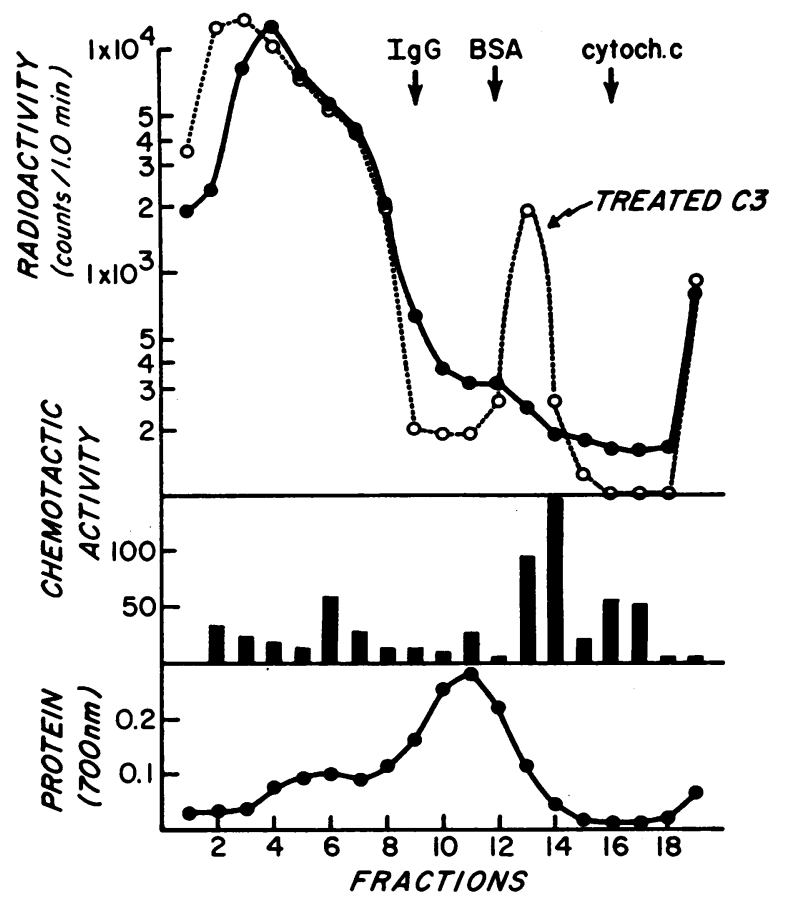

FigURE 7 Cleavage of C3 (upper frame, dotted line) by synovial fluid 15138 with appearance of slowly sedimenting chemotactic activity (middle frame) coincident with the cleavage product (fractions 13-15, upper frame). Untreated C3 shows no such cleavage product (solid line, upper frame).

erating additional activity from $\mathrm{C} 3$ was also contained within the fluid. As shown in Fig. 7, $150 \mu \mathrm{g}$ of unlabeled $\mathrm{C} 3$ and $5 \mu \mathrm{g}$ of radiolabeled C3 were treated with $50 \mu \mathrm{l}$ of synovial fluid for $30 \mathrm{~min}$ at $37^{\circ} \mathrm{C}$, and then the solution was fractionated in the density gradient. It is evident that a cleavage product of $\mathrm{C} 3$ was produced with a peak of radioactivity (Fig. 7, fractions 12-14) lying between the BSA (fraction 12) and the cytochrome c markers (fraction 16). Coincident with this radioactivity peak was the zone of maximal chemotactic activity (fractions 13,14 ). Untreated C3 contained no such peak of radioactivity in the upper zone of the gradient. These data provide direct evidence for the presence in the joint fluid of a C3-cleaving enzyme capable of releasing a chemotactic fragment from intact C3. A second fluid (15734) from a patient with inflammatory nonrheumatoid arthritis has been similarly examined and virtually identical results have been attained using a radiolabeled $\mathrm{C} 3$ preparation.

Characteristics of the C3 protease in synovial fluid 15138. Addition of $20 \mu \mathrm{l}$ of synovial fluid 15138 (a dose with insignificant chemotactic activity, $<50$ counts) to $100 \mu \mathrm{g}$ of $\mathrm{C} 3$ at $37^{\circ} \mathrm{C}$ for $\frac{1}{2} \mathrm{hr}$ led to the generation of substantial chemotactic activity (chemotactic count of 220). If $1.8 \times 10^{-2} \mathrm{M}$ EACA was present from the beginning, $87 \%$ of the chemotactic activity failed to appear. On the other hand, trypsin inhibitor was relatively ineffective, since $150 \mu \mathrm{g}$ blocked generation of only $11 \%$ of the newly appearing activity. Synthetic esters at $1.8 \times 18^{-2}$ moles/liters, present from the beginning of incubation were effective in the following manner: TAMe, $68 \%$ inhibition; BAMe, $47 \%$ inhibition; and ATEe, $27 \%$ inhibition. These experiments were controlled by also adding esters at the end of the incubation period to otherwise untreated positive controls (C3 plus synovial fluid mixture). Esters added at the end did not affect chemotactic activity. In general terms, this C3 protease is similar to that extractable from normal tissues (8).

\section{DISCUSSION}

Synovial fluids from patients with rheumatoid and inflammatory nonrheumatoid arthritis have provided a wealth of data regarding the various chemotactic mediators (as well as their generators) present in these fluids. Our studies first concentrated on rheumatoid arthritis for two reasons: the complement system is known to be importantly involved in the generation of chemotactic mediators, and there are many reasons to conclude that the complement system has been triggered in rheumatoid synovial fluids. Among these reasons are: (a) the very low level of complement activity in rheumatoid synovial fluids compared with nonrheumatoid fluids ( 9 , $10)$; $(b)$ evidence for the multicomponent reduction of the complement sequence $(11,12)$; and $(c)$ electrophoretic alteration ("conversion") of C3 in the synovial fluid (13). It seemed especially appropriate to look for chemotactic mediators in these fluids in view of the fact that rheumatoid synovial fluids characteristically contain large numbers of neutrophils, the accumulation of which might be accounted for by the presence of chemotactic factors. It was not surprising, therefore, to find chemotactic activity in a relatively high percentage $(70 \%)$ of rheumatoid fluids, and the finding of $\mathrm{C} 567$ and $\mathrm{C} 5 \mathrm{a}$ as an explanation for the chemotactic activity is consonant with the present knowledge concerning chemotactic factors derived from the complement system (14). What accounts for the presence of $\mathrm{C} 5 \mathrm{a}$ and $\mathrm{C} \overline{567}$ is far from clear. The only known mechanism for generating $\mathrm{C} \overline{567}$ is sequential interaction of the complement sequence. Agents such as the complexes containing $\gamma$-globulin and anti- $\gamma$-globulin as recently described by Hannestad (15) and by Winchester, Agnello, and Kunkel (16) may account for complement activation. Additionally, the interaction in synovial fluids of rheumatoid factor with altered $\gamma$-globulin may fire the complement system (17). On the other hand, a proteolytic enzyme such as plasmin may activate $\mathrm{C} 1$ and thus initiate the complement sequence of interactions (reviewed 
in 18). There is no clear evidence to preclude any or all of these possibilities as the explanation for the generation of $\mathrm{C} \overline{567}$ and $\mathrm{C} 5 \mathrm{a}$ in rheumatoid synovial fluids.

The finding of a C5-cleaving enzyme in rheumatoid synovial fluids can be explained by the presence of large numbers of neutrophilic granulocytes in the fluids assuming that there is a release of the C5-cleaving enzyme present in lysosomal granules of neutrophil of rabbit (4) and man (this paper and referene 19). In an inflamed rheumatoid joint, the rapid turnover of proteins from the plasma (20) makes it likely that the substrate, C5, is being rapidly delivered to that joint space. With the presence of the C5-cleaving enzyme, rapid production of $\mathrm{C} 5 \mathrm{a}$ would occur, intensifying the already acute inflammatory response by accelerating the delivery of more and more neutrophils from the circulation. The release of the C5-cleaving enzyme from neutrophils could be due either to disintegration of leukocytes in the joint fluid or through an active release mechanism such as phagocytosis. In recent unpublished work ${ }^{2}$ we have found that, like the other lysosomal enzymes, the C5-cleaving enzyme is released during phagocytosis. With the presence of immune complexes in rheumatoid synovial fluids, the stage would be set for phagocytosis and the release of the C5-cleaving enzyme.

It was of interest that nearly half the inflammatory nonrheumatoid fluids were chemotactically active, although there was no single disease entity with which a high incidence $(>50 \%)$ of chemotactically active fluid was associated. The nature of the complement-associated chemotactic activity in these fluids was quite different when compared with the rheumatoid fluids. C3 was increasingly incriminated as the source of the chemotactic activity in many of the nonrheumatoid fluids. In view of the presence of $\mathrm{C} 3$ cleavage products with chemotactic activity in these synovial fluids, it was of exceptional interest to find in these fluids a factor capable of generating additional chemotactic activity from intact C3. How, and from where, the putative C3-cleaving enzyme arises in these synovial fluids is a complete mystery. The fact that this enzyme behaves in the presence of inhibitors very similar to a C3-cleaving enzyme extracted from a variety of normal tissues of the rat and man (8), presents the possibility that the enzyme may derive from a normal tissue constituent contained within the joint. Investigations are underway to assess this possibility. It can be stated with firmness that the neutrophil is an improbable source for the C3-cleaving enzyme since we have not found a factor in human or rabbit neutrophils that can cleave C 3 into chemotactically active fragments (4). This is in line with another recent report (19).

\footnotetext{
${ }^{2}$ Ward, P. A., and N. J. Zvaifler. Manuscript in preparation.
}

Whether the C3-cleaving enzyme is thrombin or plasmin cannot be determined at the present time since both enzymes can cleave C3 into chemotatic fragments (21, 22 ), and both enzymes would be competitively inhibited by TAMe and BAMe (23). It seems unlikely that the C3-cleaving enzyme in the synovial fluids can be equated with " $\mathrm{C} 3$ convertase" $(\mathrm{C} \overline{42})$, the enzyme that is intrinsic to the complement system and utilizes $\mathrm{C} 3$ as its substrate. This possibility is unlikely for the following reasons: $(a)$ in no instance has cleavage of $\mathrm{C} 3$ by the synovial fluid enzyme described above resulted in electrophoretic conversion of $\mathrm{C} 3,{ }^{3}$ a hallmark of " $\mathrm{C} 3$ convertase;" (b) TAMe and BAMe do not interfere with C3 convertase activity; and (c) the products cleaved from $\mathrm{C} 3$ by the synovial fluid enzyme are more heterogenous and larger than the classical product generated by C3 convertase. (All these points are reviewed in reference 24.)

The finding of chemotactic activity in two of six fluids from patients with osteoarthritis is unexplained. In one, the activity was C3-related and, perhaps, explicable by the release of a $\mathrm{C} 3$-cleaving enzyme from normal tissue constituents into the joint (see above).

None of the four joint fluids from patients with systemic lupus erythematosus was chemotactically active. This was somewhat surprising since the leukocyte counts in these fluids ranged from 6.5 to $10 \times 10^{6}$ cells $/ \mathrm{mm}^{3}$. The patients are similar to those recently described by Pekin and Zvaifler (25) where the joint fluids had moderate accumulations of leukocytes, elevated protein content (including IgG), and low levels of total hemolytic complement and $\mathrm{C} 3$. This constellation of findings resembles that of rheumatoid effusions, except that the cells in the lupus synovial fluids were predominantly mononuclear in type rather than granulocytic. The absence of chemotactic activity for neutrophils in the lupus fluid may thus be reflected by the mononuclear cell content, and the lack of the C5-cleaving enzyme may be explained by the very small number of neutrophils in such fluid.

That two of three gout cases had chemotactically positive fluids could have been anticipated in view of the fact that uric acid crystals can trigger the complement sequence by activation of $\mathrm{C} 1$ (26). We found one gouty fluid rich in C5-related chemotactic activity. However, the other chemotactically active fluid had C3-, but not C5-, related activity. Whether this implies two different mechanisms (sequential and nonsequential) for generation of complement derived chemotactic factors is a question requiring further study.

\footnotetext{
${ }^{8}$ Ward, P. A., and N. J. Zvaifler. Unpublished observations.
} 


\section{ACKNOWLEDGMENTS}

This work was supported in part by National Institutes of Health Grant AI-07291, (under sponsorship of Universities Associated for Research and Education in Pathology), AM05140, and 5042 and funds from the Arthritis Foundation.

\section{REFERENCES}

1. Ward, P. A., C. G. Cochrane, and H. J. Müller-Eberhard. 1965. The role of serum complement in chemotaxis of leukocytes in vitro. J. Exp. Med. 122: 327.

2. Ward, P. A., C. G. Cochrane, and H. J. Müller-Eberhard. 1966. Further studies on the chemotactic factor of complement and its formation in vivo. Immunology. 11: 141.

3. Thompson, R. A., and P. J. Lachmann. 1970. Reactive lysis: the complement-mediated lysis of unsensitized cells. I. The characterization of the indicator factor and its identification as C7. J. Exp. Med. 131: 629.

4. Ward, P. A., and J. H. Hill. 1970. C5 chemotactic fragments produced by an enzyme in lysosomal granules of neutrophils. J. Immunol. 104: 535 .

5. Müller-Eberhard, H. J. 1960. A new supporting medium for preparative electrophoresis. Scand. J. Clin. Lab. Invest. $12: 33$.

6. Nilsson, U. R., and H. J. Müller-Eberhard. 1965. Isolation of $\beta 1 F$-globulin from human serum and its characterization as the fifth component of complement. J. Exp. Med. $122: 277$.

7. Zvaifler, N. J., and T. J. Pekin. 1963. Significance of urate crystals in synovial fluids. Arch. Intern. Med 111: 99.

8. Hill, J. H., and P. A. Ward. 1969. C3 leukotactic factors produced by a tissue protease. J. Exp. Med. 130: 505.

9. Pekin, T. J., and N. J. Zvaifler. 1964. Hemolytic complement in synovial fluid. J. Clin. Invest. 43: 1372.

10. Hedberg, H. 1967. Studies on synovial fluid in arthritis. Acta Med.Scand. Suppl. 479.

11. Zvaifler, N. J., and T. J. Pekin, Jr. 1963. Complement components in synovial fluid. Arthritis Rheum. 6: 308.

12. Ruddy, S., and K. F. Austen. 1970. The complement system in rheumatoid synovitis. I. An analysis of complement component activities in rheumatoid synovial fluids. Arthritis Rheum. 13: 713.
13. Zvaifler, N. J. 1969. Breakdown products of $\mathrm{C}^{\prime} 3$ in human synovial fluids. J. Clin. Invest. 48: 1532.

14. Ward, P. A. 1970. Neutrophil chemotactic factors and related clinical disorders. Arthritis Rheum. 13: 181.

15. Hannestad, K. 1967. Presence of aggregated $\gamma$ G-globulin in certain rheumatoid synovial effusions. Clin. Exp. Immunol. 2: 511 .

16. Winchester, R. J., V. Agnello, and H. G. Kunkel. 1969. The joint fluid $\gamma \mathrm{G}$-globulin complexes and their relationship to intraarticular complement diminution. Ann. N. $Y$. Acad. Sci. 168: 195.

17. Zvaifler, N. J., and P. Schur. 1968. Reactions of aggregated mercaptoethanol treated gamma globulin with rheumatoid factor-Precipitin and complement fixation studies. Arthritis Rheum. 11: 523.

18. Ratnoff, O. D. 1969. Some relationships among hemostasis, fibrinolytic phenomena, immunity and the inflammatory response. Advan. Immunol. 10: 145.

19. Taubman, S. B., P. R. Goldschmidt, and I. H. Lepow. 1970. Effects of lysosomal enzymes from human leukocytes on human complement components. Fed. Proc. 29: 434. (Abstr.)

20. Sliwinski, A. J., and N. J. Zvaifler. 1969. The removal of aggregated and nonaggregated autologous gamma globulin from rheumatoid joints. Arthritis Rheum. 12: 504.

21. Ward, P. A. 1967. A plasmin-split fragment of $\mathrm{C}^{\prime} 3$ as a new chemotactic factor. J. Exp. Med. 126: 189.

22. Bokisch, V. A., H. J. Müller-Eberhard, and C. G. Cochrane. 1969. Isolation of a fragment (C3a) of the third component of human complement containing anaphylatoxin and chemotactic activity and description of an anaphylatoxin inactivator of human serum. $J$. Exp. Med. 129: 1109.

23. Naff, G. B., and O. D. Ratnoff. 1968. The enzymatic nature of $C^{\prime} 1 \mathrm{r}$. Conversion of $C^{\prime} 1 \mathrm{~s}$ to $C^{\prime} 1$ esterase and digestion of amino acid esters by $C^{\prime} 1$ r. J. Exp. Med. 128: 571.

24. Müller-Eberhard, H. J., A. P. Dalmasso, and M. A. Calcott. 1966. The reaction mechanism of $\beta 1 \mathrm{C}$-globulin $\left(\mathrm{C}^{\prime} 3\right)$ in immune hemolysis. J. Exp. Med. 123: 33.

25. Pekin, T. J., and N. J. Zvaifler. 1970. Synovial fluid findings in systemic lupus erythematosus. Arthritis Rheum. 13: 777.

26. Naff, G. B., and P. H. Byers. 1967. Possible implication of complement in acute gout. J. Clin. Invest. 46: 1099. (Abstr.) 